\title{
The Quantitative Easing Bursts Bitcoin Price
}

\author{
Marco Patacca ${ }^{1} \&$ Sergio Focardi ${ }^{2}$ \\ ${ }^{1}$ Department of Economics, University of Verona, via Cantarane 24, 37129 Verona, Italy \\ ${ }^{2}$ Léonard de Vinci Pôle Universitaire, Research Center, 92916 Paris La Défense Cedex, France \\ Correspondence: Marco Patacca, Department of Economics, University of Verona, via Cantarane 24, 37129 Verona, \\ Italy.
}

Received: July 31, 2021

Accepted: August 20, 2021

Online Published: August 21, 2021

doi:10.5430/afr.v10n3p65

URL: https://doi.org/10.5430/afr.v10n3p65

\begin{abstract}
In this paper we analyze the existence of cointegrating relationships between Bitcoin, S\&P 500, and the quantity of money M2. We perform our analysis with and without applying time warping pre-processing. In all cases we find strong evidence that, in the period 2016-2021 the three time series show two cointegrating relationships and therefore share a common stochastic trend. In addition, a low correlation between Bitcoin and S\&P 500 is detected. These finding justify the increased interest of investors in Bitcoin as an alternative asset class. The economic interpretation is that the stock valuation is primarily determined by financial phenomena, in particular the availability of large quantity of money. Money supporting investment is due both to the actions of Quantitative Easing and to the exchange of creditor/debtor role that took place between households and firms. The price of both Bitcoin and stocks is increasingly influenced by the amount of money in circulation and follows the same stochastic trend.
\end{abstract}

Keywords: quantitative easing, monetary policy, bitcoin, cryptocurrencies, cointegration

\section{Introduction}

The price of Bitcoin has reached levels that would have been difficult to imagine just a few months ago. Bitcoin is the first decentralized digital currency that created the cryptocurrency sector. A cryptocurrency is a large set of electronic positions that can be transferred peer-to-peer without the need of an intermediary and that can be used to perform transactions. Stated differently, bitcoins are numbers stored in computers that represent purchasing power.

The number of bitcoins in circulation grows according to a predefined algorithm: new bitcoins are created as remuneration of the activity of miners. The miners are those individuals or organizations that validate transactions.

Bitcoin is not backed by tangible assets; its value is purely determined by the interplay of offer and demand. Now, why should anyone be willing to pay so much for something that is not backed by any real economic activity?

There is a rich literature that discusses the fundamental price and the determinants of Bitcoin value. Cheah and Fry (2015) argue that Bitcoin has no fundamental value and Bouri et al. (2019); Corbet et al. (2018); Scaillet et al. (2020) find that Bitcoin dynamic is driven by jumps, structural breaks, and bubble effects. On the other hand, Hayes (2019) shows that the marginal cost of production is the lower bound of Bitcoin prices, whilst Ciaian et al. (2016); Cretarola et al. (2018); Figa-Talamanca and Patacca (2019); Eom et al. (2019); Figà-Talamanca and Patacca (2020); Cretarola et al. (2020); Ahn and Kim (2020) investigate the main determinants of Bitcoin price such as investor attention, sentiment, or specific measures of market attractiveness. Guo (2021) studies the volatility term structure of the Bitcoin futures prices.

There are disagreements on the nature and the role of Bitcoin as financial asset. Among others, Spencer Bogart defines Bitcoin as a "Platypus", see https://www.forbes.com/, because it mixes several features from many different assets without fit neatly into any pre-existing categories. Furthermore, Amy $C$. Arnott in https://www.morningstar.com/ shows Bitcoin as a great portfolio diversifier guaranteeing higher returns more than offset the added volatility. Confirming the previous findings, we find low correlations between Bitcoin and the S\&P 500 Index.

But the recent price increase of Bitcoin, that went from 5000 dollars in March 2020 to values above 60000 dollars in April 2021, suggests looking for phenomena of great magnitude and of great impact. One such phenomenon is the monetary policy of central banks. 
The relationship of stock prices with the quantity of money M2 has been widely discussed in the literature. Studies found a strong connection of stock prices and the quantity of money, see among others Maskay and Chapman (2007); Širůček (2013); Böing and Stadtmann (2016).

Corbet et al. (2017) show that monetary interest rates policy decisions and quantitative easing announcements significantly affect the Bitcoin returns volatility and Corbet et al. (2020) find significant evidence of volatility spillover transfers from US monetary policy announcements to Currency-based digital assets.

In this paper we contribute to this strand of literature by investigating the relationship between monetary policy, Bitcoin, and traditional stock markets price dynamics. Specifically, we use the Johansen cointegration test to analyze the possible link between Bitcoin, the monetary mass M2 and S\&P 500 Index and we claim that the M2 is a factor that drives both stock markets and Bitcoin. Due to this common factor Bitcoin and stock indices share many risk-return features. We argue that the value of Bitcoin depends on the amount of money in circulation and the extreme abundance of money in modern advanced economies is one of the main reasons why investors are looking for alternative investment in directions far from traditional asset classes. Therefore, Bitcoin is increasingly viewed as a trading asset class even by institutional investors. Taken together these facts justify the strong demand and, consequently, the price increase for Bitcoin: Bitcoin and S\&P 500 share the same trend driven by M2 but, at the same time Bitcoin provide diversification effect to standard assets. Our methodology is based first on analyzing the economic rationale that might suggest investing in Bitcoin and, second, on testing for cointegration between M2, S\&P 500, and Bitcoin. The vast amount of money created by Quantitative Easing, and the households' borrowing, that creates monetary profit for firms, have pushed up stock prices. There is a widespread belief that stock prices depend on financial factors. This fact makes the behavior of stock prices more akin to that of Bitcoin and makes Bitcoin an attractive asset class. Cointegration analysis confirms this economic intuition. The rest of the paper is organized as follows: in Section 2 we describe the impact of money on financial assets; Section 3 is devoted to data description and empirical analysis and in Section 4 we offer some concluding remarks.

\section{The Impact of Money on Financial Assets}

Let us first observe that the entire US financial market has experienced a fast, albeit somewhat bumpy, growth in post-crisis period. In the period January 2009 - April 2021 both the S\&P 500 Index (Note 1) and the MSCI USA Index (Note 2) grew more than 5 times, while the US per capita nominal GDP (Note 3) grew barely 40\%. In Figure 1 we plot the three time series; the US GDP follows the right y-axis range while the others follow the left y-axis range.

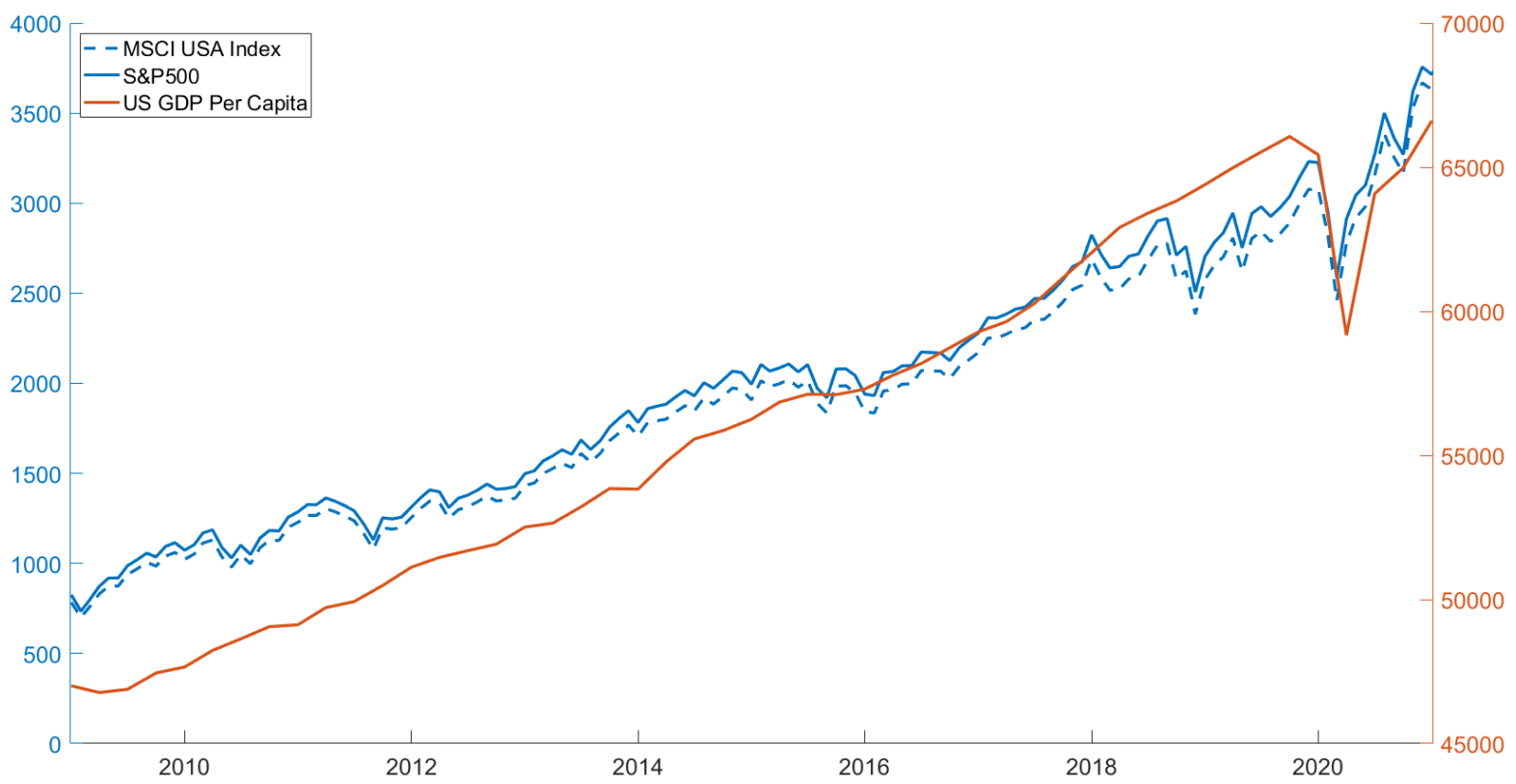

Figure 1. MSCI USA Index (dashed blue line), S\&P 500 (solid blue line) and US per capita nominal GDP (solid orange line) from January 2009 to April 2021

The modest growth of the US economy in comparison to the strong growth of US stock market capitalization 
suggests that purely financial phenomena might be responsible for the large gains of the stock market. Two important financial phenomena of great magnitude are Quantitative Easing - QE - and changes in the borrowing behavior.

Quantitative Easing started after the 2007 financial crisis. Through QE central banks purchase financial assets from non-banks. Central banks have no direct link to private firms and therefore use commercial banks to purchase assets from financial institutions such as pension funds or banks. The result is twofold: the sellers of assets receive cash and commercial banks increase their reserves.

In addition, there is a second important financial phenomenon that affected the monetary profitability of firms: in the last three to four decades, firms have progressively become net creditors while households have progressively become net debtors. That is, households are no longer net savers but net debtors, see Infante et al. (2017); Behringer (2019).

As a result, bank reserves and the monetary mass M2 increase. Figure 2 shows the evolution of bank reserves and M2 in the US from 2009 to 2021.

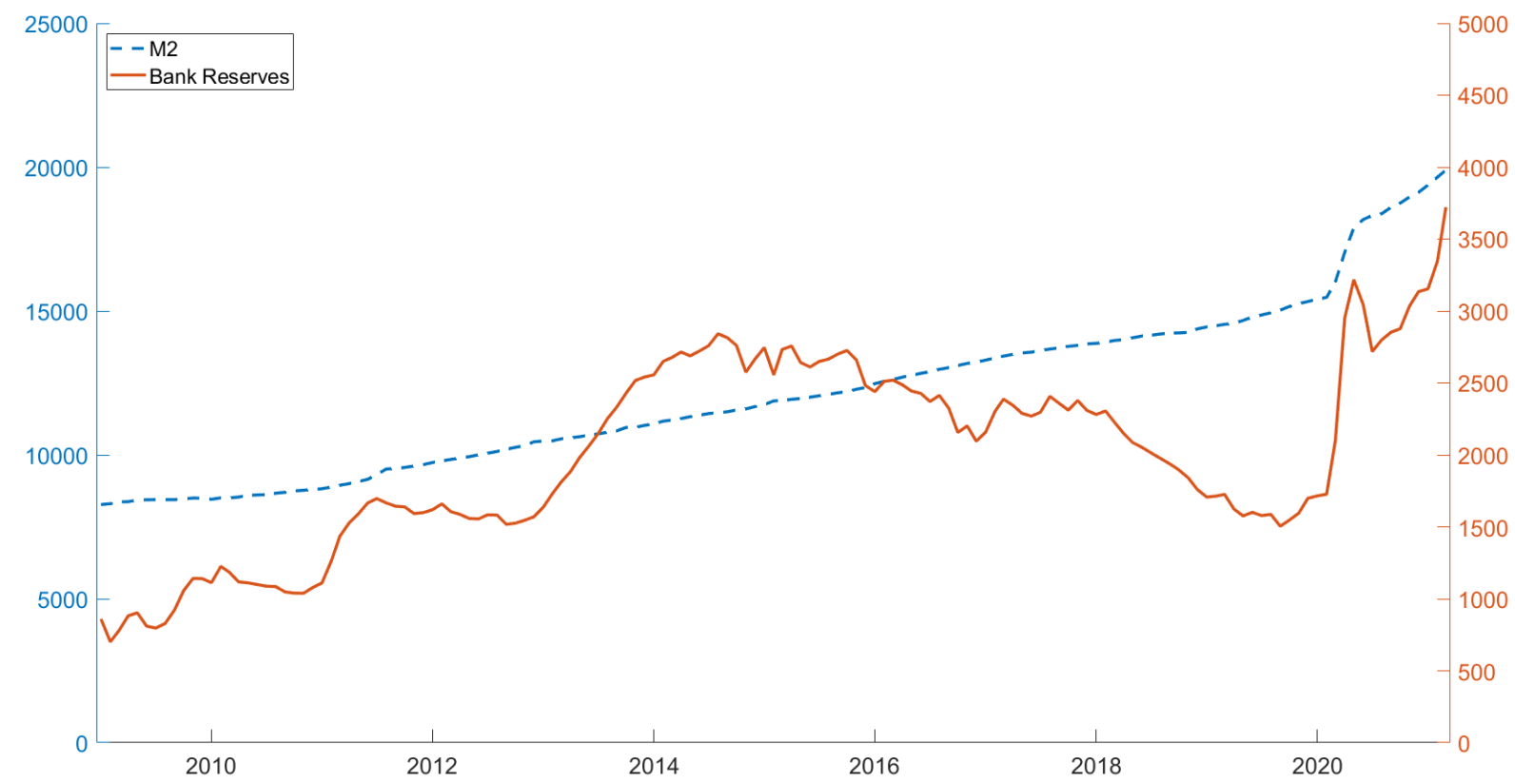

Figure 2. M2 (dashed blue line) and Bank Reserves (solid orange line) from January 2009 to March 2021

Money, that represents purchasing power, makes the demand for stocks increase and therefore pushes prices up and brings interest rates down. At the same time, due to money created by debt, households exhibit a demand for goods and services more than the salaries and pensions they receive. This demand creates monetary profit for firms and therefore increases their valuation and pushes their prices up. The combined action of QE and households' debts have pushed prices up at unprecedented levels for purely financial reasons.

An interesting indicator of the role of money in market capitalization is the Buffett Ratio. The Buffett Ratio is the ratio of total stock market valuation to GDP of a specific country. As of April 22, 2021, the Buffett Ratio for the US had the following value (Note 4):

- Aggregate US Market Value: 51.3T

- Annualized GDP (Estimate): 21.9T

- $\quad$ Buffett Ratio: $51.3 / 21.9=234 \%$

These numbers confirm that US market valuations are increasingly dominated by a demand/supply ratio primarily due to the extreme high level of money in circulation. Naturally, at the same time, this money creates monetary profit for firms.

Now, money created by the debt of households or by QE cannot grow indefinitely. Debts must be repaid, and QE is subject to political scrutiny. Therefore, market valuations related to excess money are risky. Stock markets are subject to the risk of a crash. In his Waiting for the Last Dance (Note 5) of January 5, 2021, Jeremy Grantham, 
co-founder of GMO, writes: "The long, long bull market since 2009 has finally matured into a fully-fledged epic bubble. Featuring extreme overvaluation, explosive price increases, frenzied issuance, and hysterically speculative investor behavior, I believe this event will be recorded as one of the great bubbles of financial history, right along with the South Sea bubble, 1929, and 2000 ... But this bubble will burst in due time, no matter how hard the Fed tries to support it, with consequent damaging effects on the economy and on portfolios. Make no mistake - for the majority of investors today, this could very well be the most important event of your investing lives."

Due to the high level of risk of the stock market, Bitcoin also has become an acceptable alternative asset and great portfolio diversifier for the institutional investor at least in the US. For example, both Morgan Stanley and Goldman Sachs now allow their wealth management clients the opportunity to invest in Bitcoin. In the following section we will see how the risk of a crash of stock market and of Bitcoin values can be linked to the same factors.

\section{Data and Methodology}

We collect weekly data (Note 6) for Bitcoin prices, S\&P 500 Index and monetary mass M2 by https://coinmarketcap.com/, https://finance.yahoo.com/ and https://fred.stlouisfed.org/ respectively, from January 2016 to March 2021. Figure 3 displays the dynamics of the three time series and Table 1 the summary statistics.

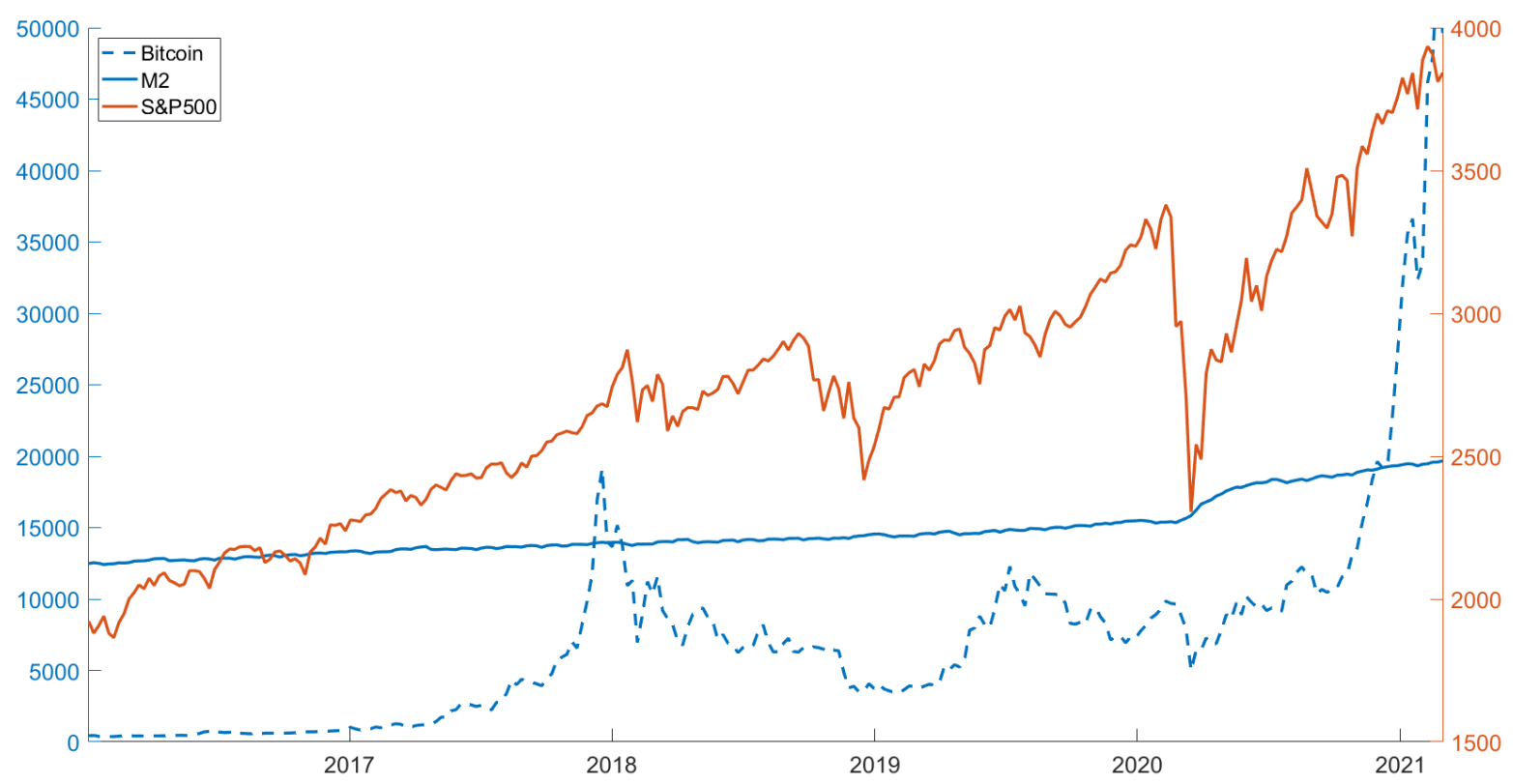

Figure 3. Weekly prices of Bitcoin (dashed blue line), M2 (solid blue line) and S\&P 500 (solid orange line)

Table 1. Summary statistics of weekly prices

\begin{tabular}{lrrr}
\hline & Bitcoin & \multicolumn{1}{c}{ M2 } & S\&P 500 \\
\hline Min. & 373.06 & 12413.70 & 1864.68 \\
Q $_{1}$ & 1250.15 & 13477.80 & 2378.25 \\
Median & 6592.52 & 14165.25 & 2733.42 \\
Mean & 7300.70 & 14776.37 & 2726.20 \\
Q $_{3}$ & 9412.61 & 15254.00 & 2972.37 \\
Max. & 54207.32 & 19677.50 & 3934.83 \\
St. Dev. & 7935.02 & 1951.76 & 468.66 \\
Skewness & 3.02 & 1.20 & 0.40 \\
Kurtosis & 15.23 & 3.31 & 2.73
\end{tabular}

Summary statistics, of weekly prices for Bitcoin, M2 and S\&P 500 Index from January 2016 to March 2021.

From Table 1 it is evident how large is the price range and the standard deviation of Bitcoin compared to the others 
time series. Moreover, we test the correlations between Bitcoin and S\&P 500 Index obtaining a value 0.1773 . This low level of correlation suggests that Bitcoin can provide diversification effect to standard assets.

In order to detect the possible long-term link between Bitcoin, M2 and the US stock market we analyse the cointegration between them. Results are reported in Table 2: the three time series are cointegrated with two cointegrating relationship; therefore, they admit one integrated common trend.

Table 2. Johansen cointegration test

\begin{tabular}{lrll}
\hline $\mathrm{r}$ & statValue & cValue & pValue \\
\hline 0 & 104.2369 & 42.9154 & 0.0010 \\
1 & 31.0739 & 25.8723 & 0.0103 \\
2 & 3.9180 & 12.5174 & 0.7617
\end{tabular}

Johansen cointegration test between Bitcoin, M2 and S\&P 500 without time warping: weekly data from January 2016 to March 2021.

To better appreciate the depth of the link between M2 and Bitcoin we test the two time series for cointegration applying or not pre-processing with time warping technique.

Time warping is a data mining methodology that stretches or contracts time to minimize the distance between the realizations of two time series. The objective is to compare the essential shape of time series even in the presence of delays.

Table 3 show that M2 and Bitcoin are cointegrated with one cointegrating relationship in both cases and, the relationship become deeper, when taking into account the delays.

Table 3. Johansen cointegration test with time warping

\begin{tabular}{rrrrrrr}
\hline & \multicolumn{2}{c}{ Data without time warping } & \multicolumn{3}{c}{ Data with time warping } \\
$\mathrm{r}$ & statValue & cValue & pValue & statValue & cValue & pValue \\
\hline 0 & 39.0709 & 25.8723 & 0.0010 & 56.0729 & 12.3206 & 0.0010 \\
1 & 9.5136 & 12.5174 & 0.1511 & 0.4425 & 4.1302 & 0.6835
\end{tabular}

Johansen cointegration test between Bitcoin and M2 weekly data from January 2016 to March 2021.

\section{Conclusion}

In this paper we find that Bitcoin, S\&P 500, and M2 are cointegrated time series suggesting that M2 is a driver of both S\&P 500 and Bitcoin. At the same time, there is a low level of correlation between Bitcoin and S\&P 500 Index.

What do the above data tell us from the point of view of investments? First, it seems reasonable to conclude that the strong cointegration between M2 and both S\&P 500 and Bitcoin is due to the exceptional financial conditions prevailing today. Specifically, the large quantity of money created by both QE and households borrowing has pushed stock prices to reach extremely high levels as illustrated by the Buffet ratio that has reached record levels. Driven by financial factors, stock prices exhibit a risk profile not too distant from that of cryptocurrency. Therefore, Bitcoin is increasingly viewed as a trading asset class even by institutional investors. Though Bitcoin is not supported by any mechanism that generates cash flows, the extreme abundance of cash seeking possible investments drives its prices up. Bitcoin and S\&P 500 are not strongly correlated, and investors might find it attractive to invest in Bitcoin from the point of view of diversification.

Of course, Bitcoin is subject to the risk of adverse regulation. At the time of this writing, Bitcoin values plunged by some $30 \%$ in a week following adverse decisions from Chinese financial authorities. If central banks and governments will decide to control the diffusion of cryptocurrencies, then the cointegration relationships that we found might break down.

Our work wants to show that strong actions by central banks such as quantitative easing are a common factor of growth for stock prices and the value of cryptocurrencies other things being equal. Regulations might force the behavior of cryptocurrencies and stock prices to diverge.

\section{Acknowledgements}

We are grateful to Gianna Figà-Talamanca for interesting discussion on the topics of the paper and very useful comments. 


\section{References}

Yongkil Ahn and Dongyeon Kim. (2020). Sentiment disagreement and bitcoin price fluctuations: a psycholinguistic approach. Applied Economics Letters, 27(5), 412-416. https://doi.org/10.1080/13504851.2019.1619013

Jan Behringer. (2019). Factor shares and the rise in corporate net lending. Technical report, IMK Working Paper, 2019.

Tobias Böing and Georg Stadtmann. (2016). Money growth and aggregate stock returns. Technical report, Discussion Paper, 2016.

Elie Bouri, Syed Jawad Hussain Shahzad, and David Roubaud. (2019). Coexplosivity in the cryptocurrency market. Finance Research Letters, 29, 178-183. https://doi.org/10.1016/j.frl.2018.07.005

Eng-Tuck Cheah and John Fry. (2015). Speculative bubbles in bitcoin markets? An empirical investigation into the fundamental value of bitcoin. Economics letters, 130, 32-36. https://doi.org/10.1016/j.econlet.2015.02.029

Pavel Ciaian, Miroslava Rajcaniova, and d'Artis Kancs. (2016). The economics of bitcoin price formation. Applied Economics, 48(19), 1799-1815. https://doi.org/10.1080/00036846.2015.1109038

Shaen Corbet, Grace McHugh, and Andrew Meegan. (2017). The influence of central bank monetary policy announcements on cryptocurrency return volatility. Investment management and financial innovations, 14(4), 60-72. https://doi.org/10.21511/imfi.14(4).2017.07

Shaen Corbet, Brian Lucey, and Larisa Yarovaya. (2018). Datestamping the bitcoin and ethereum bubbles. Finance Research Letters, 26, 81-88. https://doi.org/10.1016/j.frl.2017.12.006

Shaen Corbet, Charles Larkin, Brian Lucey, Andrew Meegan, and Larisa Yarovaya. (2020). Cryptocurrency reaction to fomc announcements: Evidence of heterogeneity based on blockchain stack position. Journal of Financial Stability, 46, 100706. https://doi.org/10.1016/j.jfs.2019.100706

Alessandra Cretarola, Gianna Figà-Talamanca, and Marco Patacca. (2018). A continuous time model for bitcoin price dynamics. In Mathematical and statistical methods for actuarial sciences and finance, pages 273-277. Springer, 2018. https://doi.org/10.1007/978-3-319-89824-7_49

Alessandra Cretarola, Gianna Figà-Talamanca, and Marco Patacca. (2020). Market attention and bitcoin price modeling: Theory, estimation and option pricing. Decisions in Economics and Finance, 43(1), 187-228. https://doi.org/10.1007/s10203-019-00262-x

Cheoljun Eom, Taisei Kaizoji, Sang Hoon Kang, and Lukas Pichl. (2019). Bitcoin and investor sentiment: Statistical characteristics and predictability. Physica A: Statistical Mechanics and its Applications, 514, 511-521. https://doi.org/10.1016/j.physa.2018.09.063

Gianna Figa-Talamanca and Marco Patacca. (2019). Does market attention affect bitcoin returns and volatility? Decisions in Economics and Finance, 42(1), 135-155. https://doi.org/10.1007/s10203-019-00258-7

Gianna Figà-Talamanca and Marco Patacca. (2020). Disentangling the relationship between bitcoin and market attention measures. Journal of Industrial and Business Economics, 47(1), 71-91. https://doi.org/10.1007/s40812-019-00133-x

Zi-Yi Guo. (2021). Price volatilities of bitcoin futures. Finance Research Letters, 102022. https://doi.org/10.1016/j.frl.2021.102022

Adam S Hayes. (2019). Bitcoin price and its marginal cost of production: support for a fundamental value. Applied Economics Letters, 26(7), 554-560. https://doi.org/10.1080/13504851.2018.1488040

Luigi Infante, T. Cesaroni, and R. De Bonis. (2017). How financial systems work: evidence from financial accounts. Banca d'Italia Working Paper, 2017.

Biniv Maskay and M Chapman. (2007). Analyzing the relationship between change in money supply and stock market prices. Illinois Wesleyan University Economics Department, 2007.

Olivier Scaillet, Adrien Treccani, and Christopher Trevisan. (2020). High-frequency jump analysis of the bitcoin market. Journal of Financial Econometrics, 18(2), 209-232. https://doi.org/10.1093/jjfinec/nby013

Martin Širůček. (2013). The impact of the money supply on stock prices and stock bubbles. Mendel University in Brno, Faculty for Business and Economics, Zemědělská, 1(613):00, 2013. https://doi.org/10.25142/aak.2014.018 


\section{Notes}

Note 1. Data from https://finance.yahoo.com/ .

Note 2. Data from https://www.msci.com/ .

Note 3. Data from https://fred.stlouisfed.org/ .

Note 4. Data from https://www.currentmarketvaluation.com/ .

Note 5. https://www.gmo.com/americas/research-library/waiting-for-the-lastdance/ .

Note 6. Weekly data are the finest time step for M2.

\section{Copyrights}

Copyright for this article is retained by the author(s), with first publication rights granted to the journal.

This is an open-access article distributed under the terms and conditions of the Creative Commons Attribution license (http://creativecommons.org/licenses/by/4.0/). 